\title{
INTERDISCIPLINARIEDAD E INTERCULTURALIDAD EN METALES PESADOS DE YANKO GONZÁLEZ CANGAS*
}

\author{
INTERDISCIPLINARY AND INTER-CULTURALITY \\ IN METALES PESADOS BY YANKO GONZÁLEZ CANGAS
}

Pilar Valenzuela Rettig

Universidad Autónoma de Chile. Santiago, Chile

valenzuela.pilar@gmail.com

\begin{abstract}
Resumen: Este artículo analiza la interdisciplinariedad e interculturalidad en Metales pesados (1998) de Yanko González Cangas, como exponente de la literatura antropológica en Chile. Se sostiene que tanto interdisciplinariedad como interculturalidad constituyen un modo de superar los límites impuestos por la ciencia antropológica y la otredad.
\end{abstract}

Palabras clave: Literatura antropológica, interdisciplinariedad, interculturalidad, otredad, Yanko González, Metales pesados.

\begin{abstract}
This paper analyzes the interdisciplinary and the inter-culturality in $\mathrm{Me}$ tales pesados (1998) by Yanko González Cangas, as exponent of the anthropologic literature in Chile. Is held that the interdisciplinary and the inter-culturality constitute manners of overcoming the limits imposed by the anthropologic science and the otherness.
\end{abstract}

Keywords: Anthropological literature, interdisciplinary, inter-culturality, otherness, Yanko González, Metales pesados.

Recibido: 05.04.2016. Aceptado: 11. 10.2016.

* El presente artículo forma parte de la investigación del Proyecto Fondecyt Postdoctoral $\mathrm{N}^{\circ} 3140616$, "Literatura antropológica en Chile: una literatura intercultural", del cual la autora es responsable. 


\section{Introducción: Metales pesados y su lectura}

$\mathrm{E}_{\mathrm{s}}$

L PRESENTE ARTículo analiza Metales pesados (1998) del antropólogo y

poeta chileno Yanko Gonzáles Cangas, como exponente de la literatura antropológica en Chile. El postulado que guía el estudio corresponde a que la obra presenta un carácter interdisciplinario e intercultural que se constituyen como un modo de superar los límites impuestos por la ciencia antropológica y la otredad.

Dentro de los estudios críticos realizados en torno a esta obra poética destacan los artículos de Hernán Neira, Juan Manuel Fierro y Walter Hoefler publicados en el año 2000, junto al de Francisca Lange (2010) y Martina Bortignon (2013). Hernán Neira determina en Metales pesados la oposición de la anestética de lo marginal a la estética de lo bello, considerando que hay una intención de producir inquietud y choque, dentro de una pretensión deconstructivista. Martina Bortignon identifica una proliferación estética en relación al imaginario social urbano sobre violencia, drogadicción y criminalidad en las pandillas juveniles marginales ${ }^{1}$. Juan Manuel Fierro considera que la obra presenta un hibridismo textual no decantado entre poesía y etnografía; califica Metales pesados como un oxímoron, al leerlo como un ejercicio dialéctico de confrontaciones discursivas de distinta naturaleza; a pesar de su estado experimental, Fierro considera que es un aporte al proceso de renovación de la lírica chilena de vanguardia. Walter Hoefler expone que Yanko González utiliza o pretende utilizar el discurso poético como modalidad indagatoria y constitutiva de ciertos sujetos específicos, validándose al mismo tiempo como poesía y como probable ciencia ${ }^{2}$.

Estos estudios se desarrollan dentro del campo literario, considerando la obra como parte de la poesía chilena. Sin embargo, también se hace po-

${ }^{1}$ Similar es la lectura de Luis Valenzuela (2011) que realiza en un artículo sobre el crimen en la ciudad y poesía de la transición chilena, donde resalta en Metales pesados la violencia, desde una construcción antropológica.

${ }^{2}$ Observamos en estos estudios una lectura de Metales pesados en relación a las subjetividades que se desarrollan en época de globalización. Al respecto, Rosenberg (2003) presenta un interesante ensayo en relación a la poesía y globalización, donde hace referencia al uso de elementos massmediáticos o de voces de tribus urbanas como formas de representaciones propias de esta época. 
sible leer la obra como "antropología poética”, la cual básicamente se entiende como un subgénero antropológico que utiliza una forma expresiva literaria ${ }^{3}$.

La justificación base para considerar que Metales pesados presenta características interdisciplinarias e interculturales se encuentra en la teoría de la literatura antropológica en Chile ${ }^{4}$. Literatura que se conforma por textos de carácter interdisciplinario entre literatura y antropología, creados por antropólogos y arqueólogos chilenos contemporáneos, que buscan una nueva escritura a partir de la necesidad de superar los límites impuestos por el discurso científico y la objetividad, como destaca Carrasco (2010: 1920). El crítico sostiene que tanto la lectura desde las ciencias sociales como desde la literatura son válidas, por lo que, desde el campo literario, se considera una literatura basada en una "mutación disciplinaria" que contiene saberes de ambas disciplinas: los textos se caracterizan por la heterogeneidad, confluencia o mezcla de géneros, contenidos y procedimientos de disciplinas distintas que coexisten en él (Cf. Carrasco, 2002, 2003 y 2010).

\section{Interdisciplinariedad: superando los límites científicos}

Nos aproximamos al proyecto de escritura del autor, a nivel metatextual, a través de la entrevista “Qué ves, Qué ves cuando me ves” realizada por el equipo de Revista Matadero (2000). En esta, Yanko González expone que Metales pesados es fruto de múltiples lecturas: literarias, etnográficas y las lecturas que corresponden a las realidades que observó participando ${ }^{5}$. De este modo, el autor define a Metales pesados como un texto interdisciplinario a través de múltiples relaciones intertextuales con libros de literatu-

\footnotetext{
${ }^{3}$ Esta inclusión se demuestra, por ejemplo, en la incorporación que realiza Alvarado (2014) de Metales pesados en el corpus de la antropología poética o literaria. Para mayor información sobre estas textualidades consultar Alvarado, 2000, 2001, 2002 y 2011.

${ }^{4}$ La literatura antropológica en Chile es identificada por el académico Iván Carrasco de la Universidad Austral de Chile a partir de una investigación Fondecyt 2010, y su mayor sustento teórico se encuentra en el artículo "Literatura antropológica chilena: fundamentos" publicado el 2010 por Estudios Filológicos.

${ }^{5}$ Dentro de las lecturas literarias se encuentran: José María Arguedas, Omar Lara, Jorge Torres y Juan Luis Martínez; y Lévi-Strauss, Tedlok y Cliford Geertz, entre las etnográficas.
} 
ra y antropología, en estrecha relación a una experiencia de observación participante en tribus juveniles marginales. Así constituye un texto que él mismo describe como:

(...) relatos fundidos, reescritos, puros y poetizados, en un juego multivocal, donde se besan la experiencia etnográfica, la observación participante y de sobremanera la autobservación. Su armazón se construyó soldando las voces particulares registradas con lápiz y grabadora, ojos y recuerdos, con la escucha social de la época señalada, sumada a la extensa herencia literaria que ha (des)escrito la moratoria juvenil. Estéticamente intenta re-crear las modalidades de discurso extraídas, pero ficcionalizando dirigidamente la tesitura de éstos al combinarlos con otra herencia mayúscula: la poética de lo feo, del exceso y del horror, que es finalmente la epoché elicitada. Extraído del otro y del mí mismo la metáfora, quedó un fondo cultural poetizado que intentó quedar en un interregno: ciencia / anticiencia, "interpretativismo grotesco", o "hermenéutica radical", pero que no renunció a sus pretensiones cognitivas y estéticas. [...] no transa con el discurso poético culterano de renunciar al lenguaje de la tribu, no. Está en slang, en jerga, porque allí radica su metáfora y su verdad. No quiere ser generalizante. Sólo pone en escena un cuerpo de textos, los manipula y descontextualiza para producir un "efecto" de representación, sin complejos cientificistas ni ficcionantes (González, 2000).

Yanko González, libre de "complejos cientificistas y ficcionantes", crea un texto interdisciplinario que se revela contra la "necesidad tarada de encapsular, encasillar y compartimentar a los demás" (González, 2000). Se evidencia la necesidad de ir en contra de la "invisibilización" del autor en el texto científico que, tal como lo sostiene Carrasco (2010), se considera una obligación para demostrar objetividad y neutralidad, y ha sido una de las razones por las cuales algunos antropólogos y arqueólogos chilenos han recurrido a la literatura como medio de expresión. También se deduce una conciencia del autor frente a la excesiva racionalización del pensamiento, que como expresa Edgar Morin (2011) es la patología del pensamiento contemporáneo: "La patología de la razón es la racionalización, que encierra a lo real en un sistema de ideas coherente, pero parcial y unilateral, y que no sabe que una parte de lo real es irracionalizable, ni que la racionalidad tiene por misión dialogar con la irracionable" (2011: 34).

A nivel de análisis textual, consideramos que la "razón" se manifiesta en 
los aspectos referenciales tanto del mundo de la tribu, como de la vida personal del poeta y sus múltiples relaciones intertextuales; mientras la "irracionalidad" queda plasmada en su lenguaje hermético ${ }^{6}$, la ambigüedad discursiva -tanto en relación al discurso poético establecido como al antropológico-, el uso del slang o jerga de las tribus juveniles -que presenta códigos lingüísticos (culturales) desconocidos por el lector promedio-, todas estrategias textuales que desorientan la interpretación, pero desencadenan una lectura sensitiva, donde impera el impacto, la fuerza, la rapidez y el desconcierto7.

En relación a la interdisciplinariedad, entendida como estrategia necesaria para superar los límites de la ciencia antropológica tradicional, destaca la sección Emperaire ${ }^{8}$. Los poemas que forman esta sección -"Derrotero de Emperaire", "Destierro de Emperaire", "Destino de Emperaire" y "Quien añade ciencia añade dolor"- aluden a "Emperaire" como una zona de orden académico a la cual el sujeto debe llegar, del cual es desterrado y en relación a un destino, pero un destino que conlleva la exclusión. Así lo interpretamos al leer los poemas en su conjunto. Primero, "Derrotero de Emperaire", nos presenta el camino del sujeto, que implica un "trote", un "paseo": "Afirmado en la música del trote / me doy a la respiración // artificial acompañado por un cono de papel // higiénico / paseo recogiendo boletas arriba de mil pesos / las // cuales tienen fines muy diversos (...)"9.

\footnotetext{
${ }^{6}$ Neira (2000) observa que parte del hermetismo del lenguaje en Metales pesados se debe a un guiño constante a claves personales, no sólo en relación a los temas de las tribus marginales, sino también, posiblemente, a la vida personal del autor.

${ }^{7}$ Como ejemplo de "irracionalidad" podemos considerar el último poema "SEPPUKU PARA KAWABATA": "para apresurar el fin/ tomarlo crudo/ digo beberlo opaco/ volver tizón tu cruz/ Barato: Vivir no pudo. Pisar la costra/ posar el beso en una uña/ calentar calostro en la cuchara poner la cuña/ ubicar la cava/ pedir el mismo espejo/ voltear un sorbo/ mirar parejo/ ESPERAR (ya viene el corvo)", un texto imposible de interpretar sin recurrir a los códigos que despliega el texto en su conjunto, a discursos metatextuales y la búsqueda de intertextualidades.

${ }^{8}$ Fierro (2000) resalta la sección en su nivel meta-etnográfico, observando que presenta "una textualización de la contradicción del observador científico y el sentir de su condición humana. Se alude a la observación de campo, al vínculo del etnógrafo con el Otro que observa y las posibilidades o distanciamiento que la ciencia positiva otorga o produce en esta relación".

${ }^{9}$ Incorporamos el signo // para separar los versos, en consideración que / es utilizado dentro de la estructura del verso, otorgando ambigüedad con respecto a la construcción de estos (puede leerse que los versos son separados por / y expuestos de forma continua, estableciendo un quiebre casual; o que el verso incluye el signo a modo de separación interna, como hemos considerado para la trascripción). El signo // se utiliza de aquí en adelante con esta intención.
} 
Un camino que se configura a partir de acciones superfluas, pero al mismo tiempo cargadas de la intimidad de un sujeto que se manifiesta en la particularidad de las pequeñas acciones cotidianas que se concretan, como "abrir definitivamente una ventana que siempre cierra a medias / y regar este cactus que se entierra en un vaso de yogurt helado" o encontrar y recoger boletas. El mismo lenguaje desordenado, hermético y caótico de las secciones anteriores se despliegan en "Derrotero de Emperaire", junto a la neurosis y soledad del sujeto que cuenta los pastelones y se salta las líneas impares del baldoserío, que no sabe bien en qué fecha está y que es feliz de cortarse al afeitarse -puesto que por lo menos la "Gillette" le demuestra un cariño-. El siguiente poema, "Destierro de Emperaire", se presenta como un extracto de un habla de otro sujeto: un académico perteneciente a Emparaire -que como voz de enunciación reemplaza a los de las tribus juvenilesque lo destierra de este espacio. Un sujeto que "le prestó ropa", pero en el presente -en el HOY con mayúsculas- lo destierra, lo abandona a partir del trabajo etnográfico que, interpretamos, corresponde a Metales pesados ${ }^{10}$.

En "Destino de Emperaire" el sujeto le responde al hablante que lo ha desterrado, desde un espacio identificado como "el canal" a donde lo "envió a flotar" el sujeto del poema anterior; es decir, el sujeto de este poema ya está desterrado y se presenta como algo que se lleva el canal de Emperaire. En esta situación de destierro, expresa que su destino son los sujetos de la observación participante y su "mirada equivocada". Concluye el poema manifestando la exclusión definitiva: "Me quedo solo al final de // la panamericana / Otros serán el busco mi destino / los sujetos de // mi observación participante / la reconocida equivocación de mi // ojo ciego", versos que se unen con el pie de página que se presenta en la hoja siguiente ${ }^{11}$, destacada con una letra de mayor tamaño que dice: "ESTE PÁRPADO QUE DICE ADIÓS es el que llora mordiendo el ojo.”. Interpretamos “ojo" y "mirada” en relación a la observación participante: una propuesta de trabajo personal que no comparte ni acepta el mundo académico tradicional (Emperaire);

10 “(...) hiciste de la pobla una canción // de Luis Miguel / un recital rancio de los The Gatos / una baladita de // Enano Verde / Yo quizás te vuelva a prestar ropa / Nadie sabe lo // que le cabe a nadie ya costrándose el hilillo de las venas / Pero HOY / //en este peladero nadie te tira un salvavidas / ni una grapa // ni una pierna (...)”.

${ }^{11}$ Por lo que podría llegar a considerarse un poema diferente, relacionado con el anterior: situación que resalta su valor en cuanto mensaje. 
interpretación que se sostiene también en el último poema de la sección, "Quien añade ciencia añade dolor". Aludiendo a una cita de Mary Shelley y el famoso Frankenstein, este poema muestra al sujeto como parte de la tribu, como un personaje más, sin "usar el pretexto de la Observación Participante" y que implica que "todo Emperaire esté con arcadas”, en clara manifestación del repudio de la acción del sujeto ${ }^{12}$.

Ante la ciencia convencional, Yanko González presenta una "mirada" distinta: un trabajo etnográfico que se escapa de lo propiamente disciplinar y se reúne con el saber literario de índole artístico, personal, íntimo, permitiendo el espacio para la irracionalidad como parte de la realidad experimentada; una mirada que construye un texto interdisciplinario. En cierta medida, Metales pesados se plantea como un contra-discurso disciplinario o académico, que se constituye como una "bravata" 13 , tal como se expresa en el primer poema -“Las tres tribus" ${ }^{14}$.

\section{Interculturalidad: más allá de la otredad}

Como hemos observado, los estudios críticos de la obra ya abordan acercamientos a la interdisciplinariedad del texto; no así la interculturalidad, elemento que planteamos en nuestra hipótesis como un espacio entre culturas, que en Metales pesados se da como una forma de superar la disciplina antropológica y la otredad ${ }^{15}$.

12 "El LOGO se inyecta entre la tribu / nada tiene que grabar // sino su sombra / nada tiene que mirar / sino su ombligo / el // / LOGO // no usará el pretexto de la Observación Participante para // chuparse todo / La estrangulación de sus pulmones será hoy el tope / para confesar lo // abierto del cedazo / la tremenda torsión // / del iris // Nunca la manada ordeñó tantos zipeproles / que el LOGO // sorbió cual orilla de playa / objeto-sujeto / todo Empeiraire con arcadas muy licuado: / la // horda manda / seguir al último candil de noite / la horda inclina por fin su lengua / y // descifra al precario traductor que aquí yace // BUITREADO".

${ }^{13}$ Bravata es definido por la Real Academia Española como "Amenaza proferida con arrogancia para intimidar a alguien.” (en línea, www.rae.es).

${ }^{14}$ En este poema el hablante -identificamos al antropólogo-poeta- se reconoce como una de las tres tribus que se baten por el amor de Bárbara, siendo él quien le escribe el poema a modo de "bravata". Para leer el poema véase el pie de página $\mathrm{N}^{\circ} 15$.

${ }^{15} \mathrm{Al}$ respecto, cabe mencionar que la hipótesis del proyecto de investigación en el cual se inserta este trabajo sostiene que: la literatura antropológica corresponde a un tipo de literatura intercultural en cuanto el sujeto antropólogo/arqueólogo presenta una mirada intercultural de la experiencia del trabajo de campo que supera la otredad; esta experiencia 
Parte de la complejidad de abordar la interculturalidad en un texto se debe a la ambigüedad del término, ante lo que se hace imprescindible aclarar su uso. En este estudio se opta por partir de un concepto de "cultura" que la entiende como procesos cuyas fronteras se encuentran en un continuo tránsito, por lo que no pueden ser consideradas monotradicionales (Fornet-Betancourt, 2002: 127-129) y que se encuentran en constante proceso de construcción debido a que se compone en la continua interacción de los seres humanos que conforman una comunidad de vida (Rodrigo, 2012: 68). Bajo esta perspectiva de cultura, se determina un concepto de interculturalidad centrado en el contacto e interacción entre culturas, donde se da una mutua influencia, el sincretismo y el mestizaje cultural (Cf. Giménez y Malgesini, 2000), diferente a lo que se entiende por interculturalidad como proyecto político, bajo un sentido normativo (Cf. Acevedo, 2008). En concreto, en el caso de Metales pesados nos referimos a relaciones interculturales interpersonales que se basan en el reconocimiento mutuo, el intercambio de saberes y experiencias, junto a la convivencia social (SERVINDI, 2005: 30).

Es necesario también explicitar el concepto de otredad que, en el presente estudio, se relaciona a una perspectiva antropológica-funcional. La otredad se identifica al objeto de estudio de la antropología y, también llamada alteridad o diversidad cultural, se ha considerado desde diversas perspectivas en antropología: primero centrada en la diferencia, luego en la diversidad y por último en la desigualdad (Cf. Boivin, Rosato y Arribas, 2004). Según Krotz (2004) no se refiera a una simple diferenciación, sino que se relaciona con la experiencia de lo extraño. Bajo esta concepción de otredad, entendemos en la experiencia de trabajo de campo, el antropólogo establece su identidad en base a un rol profesional que se constituye en oposición al otro, ante el cual establece la diferencia, desigualdad y/o extrañamiento ${ }^{16}$.

\footnotetext{
intercultural se presenta en medida que el sujeto se relaciona con el otro desde su integridad, no sólo profesionalmente, experimentando una situación intercultural que debido a su fuerza intelectual y sensitiva requiere de estrategias interdisciplinarias, antropológicas y literarias, para comunicarse.

${ }^{16}$ Por otra parte, la otredad se relaciona con la inteligencia ciega, la racionalización de la razón y la incapacidad de hacerla dialogar con la "irracionalidad" que, como expresa Morin (2011), es parte de la complejidad. A través de la interdisciplinariedad e interculturalidad, Metales pesados plantea un pensamiento complejo: supera la división entre ciencia/ arte, antropología/literatura, racionalidad/irracionalidad, sujeto/objeto.
} 
Metales pesados no ha sido analizado desde la temática intercultural en específico; sin embargo, se reconoce que, tanto el trabajo de Hernán Neira (2000) como de Juan Manuel Fierro (2000), establecen ciertos acercamientos a la temática. Neira, al analizar la enunciación de los textos las voces y el lenguaje- hace referencia a la capacidad del antropólogo de ubicarse en el lugar del otro, de "ser el otro", sostiene: "El narrador (...) habla de un sí mismo, que es, a la vez, los otros, que dejan de ser otros por el mimetismo lingüístico que rehúsa tratarlos como el objeto de una investigación y los trata como iguales". En esta cita de Neira observamos una lectura de la relación entre antropólogo-poeta con la tribu a nivel intercultural, por cuanto no se centra en la diferencia con los otros sino en su capacidad de "ser el otro". Por su parte, Fierro apunta al oxímoron como un esfuerzo por unir lo que normalmente no se puede unir; que desde nuestra lectura calificamos como una mirada intercultural, por cuanto busca unir la cultura del otro -en este caso la de las tribus de jóvenes marginales- y la del antropólogo-poeta. También Fierro destaca la fusión del sujeto con el objeto a través de la enunciación: "Ya no basta con crear al 'otro' y testimoniar que existe, hay que devolverle la identidad, insuflarle vida o dejarle vivir. Poner atención a su propio testimonio, reconocer su voz y fusionarse en ella estableciendo así el efecto transversal y horizontal de la polifonía de voces que ya no se observan o interpretan: se comparten, se fusionan, se escuchan, se imitan, se enuncian", coincidiendo con Neira en la capacidad de "ser el otro" o de "fusión" del antropólogo-poeta.

Ya en el primer poema de Metales pesados, titulado "Las tres Tribus" ${ }^{17}$, el hablante se incorpora como una de las tribus que se debaten por Bárbara quien "tiene un nuevo negro que la azota" y por cual las "tres tribus se jalan la nostalgia", incluyendo al hablante quien se identifica como la tercera tribu en el último verso, destacado gráficamente más que los demás con letras en mayúsculas y negritas: "LA TERCERA LE ESCRIBE ESTA BRAVATA", verso que se explaya a través del pie de página que corresponde a una cita

17 "Bárbara tiene un nuevo // Negro que la azota // Y tres tribus se jalan // la nostalgia // La primera le compuso la más potente canción // En un solo de bajo // "solo de bajo-bajón" "canción con bajo para Bárbara" // La segunda pateó más que nadie // En el recital de los POROTOS WITH RIENDAS // Y la tercera // LA TERCERA LE ESCRIBE ESTA BRAVATA 1". 
de Lévi-Strauss sobre el parentesco y la demanda de mujeres ${ }^{18}$. Esta declaración justifica la lectura de Neira y Fierro de considerar que Yanko González -tanto como autor empírico y textual, que proyectamos en el sujeto de enunciación del poema- presenta la capacidad de "ser el otro" o "fusionarse", estrategia discursiva que sostiene el carácter intercultural del texto, en la medida que la postura del autor no es centrarse en las diferencias, sino proyectar al Otro, a Él y la relación entre ambos en un texto donde todas las voces tienen espacio y se encuentran sin necesidad de traducción -la "traducción" cae en manos del lector, quien no comparte los códigos expuestos en el texto-.

Consideramos que Metales pesados es fruto de una relación intercultural que experimenta el autor empírico con las tribus juveniles marginales con las que comparte a raíz de un trabajo de investigación de orden etnográfico. Trabajo que deducimos se lleva a cabo en el contexto del mundo académico - "Emperaire"- y que escapa a lo que "debiera ser" -razón por la que es desterrado de "Emperaire"-. Siguiendo esta lógica, podemos llegar a postular que el trabajo de Yanko González fue más allá de la otredad -de la diferencia- y llegó a un nivel de relación que se puede calificar como intercultural.

En Metales pesados se presenta un sujeto que se identifica integralmente, como antropólogo, como poeta y como persona; que se introduce en la voz del otro, por cuanto demuestra que logra empatizar y comprender la cultura de los jóvenes. También se despliega como un hablante, no sólo en la voz del otro, sino también como una voz que dialoga, se mira a sí mismo y se proyecta como un personaje. Esta calidad de personaje se observa, por ejemplo, en el poema "Quien Añade Ciencia Añade Dolor” - presentado como una cita de Mary Shelley, autora del mítico Frankenstein- donde se constituye como EL LOGO'${ }^{19}$.

Otra forma de abordar el análisis intercultural de Metales pesados es desde la teoría de la literatura intercultural de Iván Carrasco (2005). Sosteniendo que la obra presenta un carácter intercultural podemos conside-

18 1) "Las mujeres más deseables forman una minoría. En consecuencia la demanda de mujeres está siempre, ritual o virtualmente, en estado de desequilibrio o de tensión” (Lévi-Strauss).

${ }^{19}$ Consultar pie de pág. $\mathrm{N}^{\circ} 11$. 
rarla como una manifestación de "interculturalidad literaria", que según Carrasco (2005: 64) corresponde un tipo de interculturalidad textual que manifiesta una relación entre etnias, culturas, lenguas y dialectos que se produce en textos reconocidos como literarios y que se modifican y transforman en la compleja situación de interacción o reciprocidad en que se hayan; siendo sus principales expresiones en Chile la poesía etnocultural, la literatura del exilio y la de los grupos inmigrantes.

El concepto de interculturalidad que utiliza Carrasco para definir la literatura intercultural es congruente al que hemos presentado en este estudio $^{20}$. A partir de este, define la interculturalidad literaria como "la relación entre etnias, culturas, lenguas y dialectos producida en textos reconocidos como literarios por la institución literaria chilena, que se modifican y transforman en la compleja situación de interacción o reciprocidad en que se hallan" (2005: 68). Desde estas definiciones podemos considerar que Metales pesados corresponde a una textualidad intercultural literaria por cuanto 1) manifiesta una relación entre culturas: la de las tribus urbanas juveniles marginales y la del antropólogo, 2) corresponde a un texto literario reconocido, a pesar de su interdisciplinariedad, y 3) corresponde a una textualidad que modifica textos previos ante la situación de interacción entre culturas. Sobre este último aspecto es necesario explayarnos, en vista de que los puntos anteriores ya han sido abordados en el presente estudio. Sostenemos que Metales pesados, como literatura antropológica, surge de la necesidad de constituir un nuevo discurso que permita comunicar la experiencia del trabajo de campo, más allá de las restringidas posibilidades que brinda el discurso científico (Cf. Carrasco, 2010 y Valenzuela, 2013). Como observamos en la sección Emperaire: el sujeto es consciente de que el discurso que ha creado, para dar a conocer la cultura de los jóvenes marginales y de la experiencia del trabajo de campo, no es aceptada por el mundo académico, sin embargo es su proyecto escritural y lo resiste. Así consideramos que lo explaya y sostiene en Alto Volta (2007), poemario donde identificamos una crítica a la academia y un sentimiento de exclu-

${ }^{20}$ Carrasco (2005: 65) entiende, básicamente, la interculturalidad como "un proceso de interacción entre sociedades en contacto y/o comunidades o grupos en el marco de una sociedad global, en cuanto dicha interacción provoque modificaciones recíprocas y cree espacios culturales nuevos resultantes de la interacción y transformación de elementos culturales heterogéneos". 
sión, junto a una preocupación de innovación en el lenguaje. Metales pesados es un texto novedoso que surge de la experiencia del trabajo de campo con las tribus juveniles y se constituye a partir de la "mutación" resultante en la mezcla de los discursos del otro -las tribus-y del autor, que desde su condición de antropólogo y poeta, recurre a códigos discursivos de ambos campos del saber. Por ende, afirmamos que la obra es producto del encuentro intercultural del autor, que recurre a la construcción de un texto que le permite dar a conocer al otro, desde la apropiación del lenguaje de este y una postura enunciativa que se sitúa en el otro y su cultura -incluyendo lenguaje, pero también todos los códigos culturales que se transmiten mediante este-, al mismo tiempo que le permite explayarse como sujeto integral -antropólogo y poeta-. Esta construcción textual manifiesta un cambio en el sujeto luego del contacto con otra cultura y cumple la condición de textos literarios reconocidos como interculturales por cuanto "se modifican y transforman en la compleja situación de interacción o reciprocidad en que se hallan" (Carrasco, 2005: 68).

Además, consideramos que Metales pesados presenta elementos destacados en la literatura intercultural: dar cuenta de una situación de esta índole, la doble codificación, una enunciación sincrética, intercultural o heterogénea y la intertextualidad (Cf. Carrasco, 2005). Determinamos una situación intercultural en cuanto el sujeto presenta un contacto con una cultura diferente, comparte con ellos y se apropia de sus códigos, en especial el lingüístico, para construir un texto que da cuenta de la cultura y de su relación con ellos. La doble codificación se presenta en relación a la interdisciplinariedad, por cuanto despliega códigos literarios y antropológicos, y también en la medida que presenta códigos de la cultura del otro y de los antropólogos -en relación al mundo académico, como observamos en Emperaire-. Con respecto a la enunciación: se presenta una enunciación heterogénea, donde una voz no identificada representa "la voz de los jóvenes marginales", hablando desde el grupo cultural, no desde la individualidad. Por último, la intertextualidad, que en la literatura intercultural de carácter etnocultural es de carácter "transliteraria" -por cuanto se establece una relación transtextual con textos y textualidades de índole no artística-, en Metales pesados se observa una intertextualidad múltiple, 
que establece relaciones con la antropología, la literatura y la cultura del grupo en estudio ${ }^{21}$.

\section{Conclusiones}

Metales pesados corresponde a una manifestación de literatura antropológica en Chile y, como tal, presenta características de interdisciplinariedad e interculturalidad. Ambas estrategias textuales se desarrollan como una forma de superar los límites discursivos propios del discurso antropológico tradicional -artículo científico- y la otredad.

Con respecto al análisis de la interdisciplinariedad en Metales pesados, a nivel metatextual, se sostiene que es un texto que reúne etnografía-poesía y sujeto-objeto, que busca producir una representación sin complejos cientificistas ni ficcionantes. Se identifica una sensación de exclusión de los cánones científico-académicos tradicionales, lo que consideramos que corresponde a una afirmación de proyecto escritural interdisciplinario.

En cuanto al análisis de la interculturalidad, se asume un concepto no normativo de esta, centrado en el contacto e interacción entre culturas, donde hay reconocimiento y aprendizaje; en específico se habla de interculturalidad en la obra enfocada a relaciones de esta condición entre personas. Identificamos un hablante que se considera como un personaje más, que interactúa con los otros compartiendo los códigos culturales aprendidos durante la convivencia. El conocimiento cultural se traduce en una estrategia enunciativa de "hablar desde el otro", ya sea como sujeto no identificado o a través de la reconstrucción del habla a partir de fragmentos enunciativos de los sujetos -a modo de selección de fragmentos de entrevistas-. Considerando la otredad desde una perspectiva antropológica funcional -que implica una mirada que se centra en el extrañamiento, la diferencia,

\footnotetext{
${ }^{21}$ Por ejemplo, hacia el campo de la antropología se establece una relación intertextual a Evans-Pritchard, Lévi-Strauss y Emperaire; a Verlaine, Mary Shelley y Omar Lara, hacia literatura; y hacia la cultura de las tribus se hace referencia a grupos como los Hip-Hop o los Hard-Core; también se presentan citas de diferentes personas a manera de "segmentos de entrevistas" - propias de un trabajo etnográfico- que se relacionan al mundo de las tribus, entre ellos: Vilhena, Dolfo y Mediano.
} 
diversidad o desigualdad- consideramos que esta se supera mediante la interculturalidad, por cuanto el sujeto se ubica en el espacio enunciativo del otro para dar su discurso: es decir, demuestra que a partir de la convivencia y la empatía, es capaz de hablar desde el otro, transformándose en el otro en el texto y desde ese espacio de "fusión" enunciar la realidad de este. También justificamos la interculturalidad en cuanto el sujeto se presenta como un personaje que comparte con los otros; se incluye en las actividades de estos compartiendo los códigos culturales, manifestando que esta acción va más allá de la labor etnográfica, por cuanto interpretamos que supera la actitud de otredad propia de esta actividad de índole investigativa. Podemos deducir que así como se manifiesta que su texto queda fuera de los discursos académicos, también su labor etnográfica -la experiencia del autor empírico- está al margen de lo impuesto por el campo antropológico tradicional, académico: esto implica que así como supera la disciplina en lo textual, también supera la otredad en lo extratextual.

Por otro lado, proponemos leer la interculturalidad en Metales pesados al considerarla como una manifestación de interculturalidad literaria, estableciendo sus similitudes con las literaturas interculturales en Chile. Sostenemos que esta lectura se valida en cuanto: manifiesta una relación entre culturas, corresponde a un texto literario reconocido y modifica textualidades ante la situación de interacción entre culturas. Junto a estas características, presenta otras que son determinantes en la teoría de estas literaturas, sobre todo en cuanto al proyecto etnocultural: dar cuenta de una situación de esta condición, la doble codificación, una enunciación sincrética, intercultural o heterogénea y la intertextualidad.

\section{Referencias}

Acevedo, S. (2008). La interculturalidad: sus orígenes como concepto y sus diferentes interpretaciones. En CANEK-Observatorio Cultural (ed.), La construcción de comunicación intercultural aplicada (pp. 139-193). Ciudad de Guatemala: El Librovisor.

Alvarado, M. (2000). Los últimos poetas de la aldea. Notas sobre la antropología como posibilidad hermenéutica. Revista Austral de Ciencias Sociales, 4, 151-166. 
. (2001). La antropología poética chilena como textualidad híbrida. Tesis de Doctorado. Valdivia: Universidad Austral de Chile.

. (2002). Introducción a la antropología poética chilena. Estudios Filológicos, 37, 169-183.

. (2011). La antropología literaria. Aportes para la generación de un lenguaje intercultural. Santiago de Chile: Cuarto Propio.

. (2014). La antropología literaria. Apuntes teóricos sobre su poblada soledad. Literatura y Lingüística, 30, 135-162.

Boivin, M., Rosato, A., Arribas, V. (2004). Constructores de otredad. Una introducción a la antropología social. Buenos Aires: Antropofagia.

Bortignon, M. (2013). Visibilización performática en Metales pesados de Yanko González. Taller de Letras, 53, 23-37.

Carrasco, I. (2002). Interdisciplinariedad, interculturalidad y canon en la poesía chilena e hispanoamericana actual. Estudios Filológicos, 37, 199-210.

. (2003). La antropología poética como mutación disciplinaria. Estudios Fílológicos, 38, 7-17.

. (2005). Literatura intercultural chilena: proyectos actuales. Revista Chilena de Literatura, 66, 63-84.

. (2010). La literatura antropológica chilena: fundamentos. Estudios Filológicos, 46, 9-23.

Fierro, J. M. (2000). Metales pesados: disonancia, oxímoron e hibridismo. El viaje etnográfico hacia una nueva tipología textual. A Parte Rei: Revista de Filosofía. Disponible en http://serbal.pntic.mec.es/AParteRei/metales. pdf.

Fornet-Betancourt, R. (2002). Filosofía intercultural en América Latina: intento de introducción no filosófica. Coord. Graciano González. El discurso intercultural. Prolegómenos a una filosofía intercultural (pp. 123-138). Madrid: Biblioteca Nueva.

Giménez, C., Malgesini, G. (2000). Guía de conceptos sobre migraciones, racismo e interculturalidad. Madrid: Los libros de la Catarata.

González, Y. (1998). Metales pesados. Valdivia: El Kultrún.

. (2000) "Qué ves, Qué ves cuando me ves". Entrevista a Yanko González. Revista Matadero. Primer número. Disponible en http://www.letras. s5.com/yg211105.htm.

. (2007). Alto Volta. Valdivia: El Kultrún.

Hoefler, W. (2000). 'No sabrás nunca de qué forma': Acercamiento a la poesía de Yanko González. Revista Logos, 10, 127-138.

Krotz, E. (2004). Alteridad y pregunta antropológica. En M. Boivin, A. Rosato y V. Arribas (eds.), Constructores de otredad. Una introducción a la antropología social (pp. 34-47). Buenos Aires: Antropofagia. 
Lange, F. (2010). Críticos y extranjeros: Enrique Lihn y Yanko González. ¿Qué es ser un escritor chileno? Revista Chilena de Literatura, 77. Disponible en http://www.revistas.uchile.cl/index.php/RCL/article/viewFile/9044/9003.

Morin, E. (2011). Introducción al pensamiento complejo. Barcelona: Gedisa.

Neira, H. (2000). Anestética de Metales pesados, de Yanko González Cangas. Estudios Filológicos, 35, 207-221.

Rodrigo, M. (2012). La comunicación intercultural. Barcelona: Anthropos Editorial.

Rosenberg, F. (2003). La razón poética en tiempos de globalización. Revista de Crítica Literaria Latinoamericana, 58, 39-55.

SERVINDI. (2005). Ed. R. Lozano. Interculturalidad: desafio y proceso en construcción. Manual de capacitación. Lima: SINCO.

Valenzuela, L. (2011). La escena del crimen: ciudad y poesía en la transición chilena. Alpha, 32, 61-76.

Valenzuela, P. (2013). El diario de viaje / campo como literatura antropológica en Chile. Tesis de Doctorado. Valdivia: Universidad Austral de Chile. 